\title{
GMR
}

\section{Case study of a patient presenting both type II bipolar affective disorder and Klinefelter syndrome}

\author{
H. Delavenne ${ }^{1}$, J.M. Khoury ${ }^{1}$, F. Thibaut ${ }^{2}$ and F.D. Garcia ${ }^{1,3}$ \\ ${ }^{1}$ Departamento de Psiquiatria e Programa de Pós-Graduação em Medicina \\ Molecular, Universidade Federal de Minas Gerais, Belo Horizonte, MG, Brasil \\ ${ }^{2}$ Department of Psychiatry, University Hospital Cochin (site Tarnier), \\ University of Paris-Descartes, INSERM U 894 Centre Psychiatry and \\ Neurosciences, Paris, France \\ ${ }^{3}$ Institute for Research and Innovation in Biomedicine, Rouen University, \\ INSERM Unit 1073, Rouen, France \\ Corresponding author: F.D. Garcia \\ E-mail: fredgarcia@ufmg.br
}

Genet. Mol. Res. 15 (4): gmr15048872

Received June 10, 2016

Accepted August 8, 2016

Published October 17, 2016

DOI http://dx.doi.org/10.4238/gmr15048872

Copyright (C) 2016 The Authors. This is an open-access article distributed under the terms of the Creative Commons Attribution ShareAlike (CC BY-SA) 4.0 License.

\begin{abstract}
Klinefelter syndrome (KS) is the most common sex chromosomal disorder with an estimated prevalence of 1 in 500-1000. Increased incidences of anxiety, depression, substance abuse, psychotic and behavioral disorders, and sexual disorders have been reported in patients with KS. The aim of this case study was to report a case of a man with untreated KS who was also diagnosed with type II bipolar disorder. This case report raises awareness regarding psychiatric diagnoses that may be associated with such a highly prevalent
\end{abstract}


condition. A 46-year-old man who had previously been diagnosed with an untreated KS was examined in our Psychiatric Department with an acute hypomanic episode. Clinical improvement was observed within 4 days and psychiatric symptoms were resolved in 7 days without use of medication. A psychiatric history of a depressive episode and at least two hypomanic episodes, as well as a family history of two relatives diagnosed with bipolar disorder, strongly suggest that our patient has type II bipolar disorder. Bipolar disorder may be a comorbid disorder in patients with KS. Routine screening for mood disorders and appropriate referral and evaluation should be performed. Future genetic research is warranted to explore why some chromosomal abnormalities (e.g., duplications), especially those located on the X chromosome, such as Klinefelter syndrome, may be associated with a bipolar or psychotic disorder in some individuals but not in others.

Key words: Klinefelter syndrome; Sex chromosomal disorder; Bipolar disorder

\section{INTRODUCTION}

Klinefelter syndrome (KS) is the most common sex chromosomal disorder with an estimated prevalence of 1 in 500-1000 newborn boys (Lanfranco et al., 2004). Individuals with KS carry a supernumerary X chromosome and may present a very broad phenotypic spectrum with physical characteristics such as a small testicular size, gynecomastia, euchanoid body habitus, sparse body hair, long arms and legs, elevated gonadotropins, and infertility (Slim et al., 2009; Radicioni et al., 2010; Zhang et al., 2015). The cognitive phenotype in individuals with KS is characterized by a small downward shift in average overall intelligence quotient (IQ). The downward shift in mean IQ seems to be driven by deficits in the verbal-conceptual domain (Boada et al., 2009). Increased incidences of anxiety, depression, substance abuse, and psychotic disorders have been reported in patients with KS (Hambert, 1964; Roy, 1981; DeLisi et al., 2005; Cederlöf et al., 2014). Our aim was to report the case of a man with untreated KS, who was also diagnosed with type II bipolar disorder (BD). This case report raises awareness regarding psychiatric diagnoses that may be associated with such a highly prevalent condition.

\section{CASE PRESENTATION}

A 46-year-old man, previously diagnosed with an untreated KS by karyotype following a diagnosis of infertility, was admitted to the Infectology Department of a University Hospital with dyspnea, thoracic pain, and fever. Physical examination revealed right lung communityacquired pneumonia. The patient was treated with amoxicillin and clavulanic acid $(1 \mathrm{~g} / 125$ $\mathrm{mg}$ ) b.i.d., paracetamol for analgesia, a low molecular weight heparin (tinzaparin), and tramadol $(50 \mathrm{mg})$ taken when needed as an analgesic. The patient's medical history indicated a depressive episode 8 years earlier, which was treated with psychotherapy without any known psychotropic treatment. No alcohol, drugs, or medication consumption was reported. The patient's mother and a maternal aunt were previously diagnosed with bipolar disorder.

On day 2 of hospitalization, the patient had no fever or pain and presented a decreased

Genetics and Molecular Research 15 (4): gmr15048872 
need for sleep, mood exaltation, inflated self-esteem, hypersyntonia, distractibility, and flight of ideas. Symptoms were not severe enough to impair normal functioning; however, an acute hypomanic state was suggested. No confusion or delusional symptoms were observed at any time. Symptoms were assessed using the Young Mania Rating Scale (Favre et al., 2003). The patient has a total score of 26/60. The patient refused all psychotropic treatment other than Zopiclone $(7.5 \mathrm{mg})$ for the sleep disorder, as he described previous episodes in which he had the same symptoms, which were resolved spontaneously. Clinical improvement was observed within 4 days and psychiatric symptoms were resolved in 7 days.

\section{DISCUSSION}

Individuals with KS have a higher risk of developing psychiatric disorders (Bruining et al., 2009), although reported symptoms have been described as heterogeneous, atypical, and often transnosographic (Slim et al., 2009; Verri et al., 2010). A 68\% prevalence of depressive symptoms has been reported in 310 adolescents with KS (Turriff et al., 2011). Another study investigated the association between KS and psychiatric disorders in 51 children and adolescents and reported a $65 \%$ prevalence of language disorders. In addition, $63 \%$ of the patients had attention-deficit hyperactivity disorder, $27 \%$ had an autism spectrum disorder, and $12 \%$ had a psychotic disorder (Bruining et al., 2009). During adulthood, patients with KS have an increased prevalence of psychiatric disorders, with attention-deficit hyperactivity disorder and psychotic syndrome the most prevalent of these disorders (Nielsen and Wohlert, 1990; Kebers et al., 2002). An association between BD and Klinefelter syndrome has rarely been reported in the literature (Everman and Stoudemire, 1994).

A psychiatric history of a depressive episode, at least two hypomanic episodes, and a family history of two relatives diagnosed with BD strongly suggest that our patient presented a type II BD. Two hypotheses could be posed in regard to this psychiatric comorbidity in an individual with KS. The first hypothesis, which is based on the family history, is that our patient has two different diagnoses with distinct etiologies. The second hypothesis is that BD may be influenced by the patient's extra X chromosome.

Supporting the hypothesis that KS can be a risk factor for BD, several studies have highlighted the association between 47,XXY aneuploidy and psychiatric disorders, such as depression, anxiety, and schizophrenia (Bender et al., 1999; van Rijn et al., 2005; Bruining et al., 2009, 2010).

Genetic studies have investigated individuals with KS because of their increased risk for schizophrenia (van Rijn et al., 2005; Bruining et al., 2010). DeLisi et al. (2005) investigated $\mathrm{KS}$ as a genetic model for psychotic disorders. It was hypothesized that, in KS, genes on the extra X chromosome escape inactivation and are expressed, altering both gray and white matter and development of the frontal and temporal lobes. These structural brain anomalies may be responsible for the development of psychiatric disorders in patients with KS (DeLisi et al., 2005; van Rijn et al., 2006).

A recent study provided evidence of genetic loci on the $\mathrm{X}$ chromosome contributing to mood disorders with juvenile onsets. There is evidence of linkage across a large region of chromosome Xq spanning two regions from Xq24 to Xq28, which have previously been linked to BD (Wigg et al., 2009).

A recent neuroimaging study in individuals with KS indicated that there are differences in some brain regions that may be involved in the onset of some psychiatric diseases. Shen et

Genetics and Molecular Research 15 (4): gmr15048872 
al. (2004) studied brain morphometry variations associated with KS. A pronounced volume reduction in brains of individuals with KS compared to healthy controls was observed in the insula, temporal gyri, amygdala, hippocampus, cingulate, and occipital gyri. Most of these regions contain gray matter structures (Shen et al., 2004). These results may lead to more research on psychiatric comorbidities in individuals with KS aimed at better understanding the abnormalities in these individuals.

We were not able to find any research regarding the treatment of patients with comorbid KS and BD. Kawahara et al. (2015) reported the use of testosterone as a mood stabilizer in a case report.

Future genetic research is warranted to explore why some chromosomal abnormalities (e.g., duplications), especially those located on the X chromosome, such as Klinefelter syndrome, may be associated with psychotic disorders or mood disorders in some individuals but not in others. However, our conclusions should be considered with care, considering that they are based on a unique case.

Clinically, screening for mood disorder and other psychiatric comorbidities is warranted in individuals with KS (Nielsen and Wohlert, 1990; Kebers et al., 2002). A careful clinical evaluation and psychiatric treatment when necessary may help individuals with KS cope with these frequent comorbidities.

\section{Conflicts of interest}

The authors declare no conflict of interest.

\section{ACKNOWLEDGMENTS}

Research partially supported by FAPEMIG (Fundação de Amparo à Pesquisa do Estado de Minas Gerais, Brazil).

\section{REFERENCES}

Bender BG, Harmon RJ, Linden MG, Bucher-Bartelson B, et al. (1999). Psychosocial competence of unselected young adults with sex chromosome abnormalities. Am. J. Med. Genet. 88: 200-206. http://dx.doi.org/10.1002/(SICI)1096$\underline{8628(19990416) 88: 2<200:: \text { AID-AJMG18>3.0.CO;2-3 }}$

Boada R, Janusz J, Hutaff-Lee C and Tartaglia N (2009). The cognitive phenotype in Klinefelter syndrome: a review of the literature including genetic and hormonal factors. Dev. Disabil. Res. Rev. 15: 284-294. http://dx.doi.org/10.1002/ddrr.83

Bruining H, Swaab H, Kas M and van Engeland H (2009). Psychiatric characteristics in a self-selected sample of boys with Klinefelter syndrome. Pediatrics 123: e865-e870.http://dx.doi.org/10.1542/peds.2008-1954

Bruining H, van Rijn S, Swaab H, Giltay J, et al. (2010). The parent-of-origin of the extra X chromosome may differentially affect psychopathology in Klinefelter syndrome. Biol. Psychiatry 68: 1156-1162. http://dx.doi.org/10.1016/j. biopsych.2010.08.034

Cederlöf M, Ohlsson Gotby A, Larsson H, Serlachius E, et al. (2014). Klinefelter syndrome and risk of psychosis, autism and ADHD. J. Psychiatr. Res. 48: 128-130.http://dx.doi.org/10.1016/j.jpsychires.2013.10.001

DeLisi LE, Maurizio AM, Svetina C, Ardekani B, et al. (2005). Klinefelter's syndrome (XXY) as a genetic model for psychotic disorders. Am. J. Med. Genet. B. Neuropsychiatr. Genet. 135B: 15-23. http://dx.doi.org/10.1002/ ajmg.b. 30163

Everman DB and Stoudemire A (1994). Bipolar disorder associated with Klinefelter's syndrome and other chromosomal abnormalities. Psychosomatics 35: 35-40. http://dx.doi.org/10.1016/S0033-3182(94)71805-3

Favre S, Aubry JM, Gex-Fabry M, Ragama-Pardos E, et al. (2003). Translation and validation of a French version of the Young Mania Rating Scale (YMRS). Encephale 29: 499-505.

Genetics and Molecular Research 15 (4): gmr15048872 
Hambert G (1964). Psychiatric symptoms in males with chromatin-positive Klinefelter syndrome - personality and neuropsychiatric complications. Acta Psychiatr. Scand. 40 (Suppl. 180): 101.

Kawahara K, Jono T, Nishi Y, Ushijima H, et al. (2015). Effects of testosterone therapy on bipolar disorder with Klinefelter syndrome. Gen. Hosp. Psychiatry 37: 192 e191-192.

Kebers F, Janvier S, Colin A, Legros JJ, et al. (2002). What is the interest of Klinefelter's syndrome for (child) psychiatrists? Encephale 28: 260-265.

Lanfranco F, Kamischke A, Zitzmann M and Nieschlag E (2004). Klinefelter's syndrome. Lancet 364: 273-283. http:// dx.doi.org/10.1016/S0140-6736(04)16678-6

Nielsen J and Wohlert M (1990). Sex chromosome abnormalities found among 34,910 newborn children: results from a 13-year incidence study in Arhus, Denmark. Birth Defects Orig. Artic. Ser. 26: 209-223.

Radicioni AF, De Marco E, Gianfrilli D, Granato S, et al. (2010). Strategies and advantages of early diagnosis in Klinefelter's syndrome. Mol. Hum. Reprod. 16: 434-440. http://dx.doi.org/10.1093/molehr/gaq027

Roy A (1981). Schizophrenia and Klinefelter's syndrome. Can. J. Psychiatry 26: 262-264.

Shen D, Liu D, Liu H, Clasen L, et al. (2004). Automated morphometric study of brain variation in XXY males. Neuroimage 23: 648-653.http://dx.doi.org/10.1016/j.neuroimage.2004.08.018

Slim I, Kissi YE, Ayachi M, Maaroufi-Beizig A, et al. (2009). Diagnosis and treatment difficulties of psychiatric symptoms in Klinefelter syndrome: a case report. BMJ Case Rep. 2009: 2009. http://dx.doi.org/10.1136/bcr.08.2008.0741

Turriff A, Levy HP and Biesecker B (2011). Prevalence and psychosocial correlates of depressive symptoms among adolescents and adults with Klinefelter syndrome. Genet. Med. 13: 966-972. http://dx.doi.org/10.1097/ GIM.0b013e3182227576

van Rijn S, Aleman A, Swaab H and Kahn RS (2005). Neurobiology of emotion and high risk for schizophrenia: role of the amygdala and the X-chromosome. Neurosci. Biobehav. Rev. 29: 385-397. http://dx.doi.org/10.1016/j. neubiorev.2004.11.005

van Rijn S, Swaab H, Aleman A and Kahn RS (2006). X Chromosomal effects on social cognitive processing and emotion regulation: A study with Klinefelter men (47,XXY). Schizophr. Res. 84: 194-203. http://dx.doi.org/10.1016/j. schres.2006.02.020

Verri A, Cremante A, Clerici F, Destefani V, et al. (2010). Klinefelter's syndrome and psychoneurologic function. Mol. Hum. Reprod. 16: 425-433.http://dx.doi.org/10.1093/molehr/gaq018

Wigg K, Feng Y, Gomez L, Kiss E, et al. (2009). Genome scan in sibling pairs with juvenile-onset mood disorders: Evidence for linkage to $13 \mathrm{q}$ and Xq. Am. J. Med. Genet. B. Neuropsychiatr. Genet. 150B: 638-646. http://dx.doi. org/10.1002/ajmg.b.30883

Zhang M, Fan HT, Zheng HS, Zhang QS, et al. (2015). Clinical characteristics of men with non-mosaic Klinefelter syndrome in northeastern China: implications for genetic counseling. Genet. Mol. Res. 14: 10897-10904. http:// dx.doi.org/10.4238/2015.September.9.27

Genetics and Molecular Research 15 (4): gmr15048872 